\title{
РЕЙТИНГ СУБЪЕКТОВ РОССИЙСКОЙ ФЕДЕРАЦИИ ПО УРОВНЮ РАЗВИТИЯ СОПРОВОЖДАЕМОГО ПРОЖИВАНИЯ ИНВАЛИДОВ
}

В статье анализируется новое направление в комплексной реабилитации и абилитации людей с инвалидностью-сопровождаемое проживание. По результатам оценки уровня развития и динамики составлен рейтинг субъектов Российской Федерации, который дает возможность сравнить позиции регионов, выявить их сильные и слабые стороны, а также является инструментом для разработки мер и планирования мероприятий по дальнейшему совершенствованию этого направления. Исследование проведено по результатам анализа материалов ежегодного мониторинга, представленных исполнительными органами власти всех субъектов Российской Федерации. В качестве критериев оценки учитывались десять индикаторов, отражающих системность и эффективность развития сопровождаемого проживания. Для обработки результатов использовались методы параметрической статистики. В результате все субъекты распределены на группы- от очень высокого уровня до крайне низкого. Выявлены регионы-лидеры и аутсайдеры по развитию сопровождаемого проживания, определены мероприятия, позволившие занять отдельным субъектам лидирующее положение в рейтинге, изучены проблемы, затрудняющие внедрение технологий в отстающих субъектах и предложены меры воздействия для улучшения работы в этом направлении. Как показало исследование, наличие большого количества регионов, с уровнем и развитием ниже среднего, свидетельствует, что

Людмила Александровна Кожушко- к.мед.н., руководитель, отдел социальной реабилитации и абилитации инвалидов, «Федеральный научный центр реабилитации инвалидов им. Г.А. Альбрехта» Министерства труда и социальной защиты Российской Федерации, Санкт-Петербург, Россия. Электронная почта: 1.timch@mail.ru

Оксана Николаевна Владимирова- к.мед.н., директор, институт социальной реабилитации и абилитации инвалидов, «Федеральный научный центр реабилитации инвалидов им. Г.А. Альбрехта» Министерства труда и социальной защиты Российской Федерации, Санкт-Петербург, Россия. Электронная почта: vladox1204@yandex.ru 
становление технологий сопровождаемого проживания находится на начальном этапе развития. Основными мерами для повышения уровня реализации программ сопровождаемого проживания являются: разработка нормативных и методических документов в этой области; формирование реестра нуждающихся в данной форме жизнеустройства; разработка регламентов предоставления социальных услуг с целью сопровождаемого проживания; организация, координация и межведомственное взаимодействие по вопросам сопровождаемого проживания; определение источников финансирования технологий; обучение специалистов; проведение информационной работы среди населения. Предложенные мероприятия могут быть использованы для совершенствования программ по развитию сопровождаемого проживания и определению подходов к деинституализации интернатной системы России в целом.

Ключевые слова: сопровождаемое проживание, инвалидность, качество жизни, рейтинг субъектов РФ

DOI: 10.17323/727-0634-2021-19-4-701-714

В последние годы в России активно внедряется новая стационарозамещающая технология социального обслуживания - сопровождаемое проживание, предусматривающая предоставление людям с инвалидностью услуг и мероприятий по социальному сопровождению в привычной и благоприятной среде (Приказ Минтруда России 2018). Внедрение этих технологий происходит поэтапно и включает подготовительный этап, учебное сопровождаемое проживание и проживание на постоянной основе. При этом проживать люди с инвалидностью могут индивидуально или малыми группами (до 7 чел.). Предусмотрено использование помещений жилого фонда всех видов и любой формы собственности. Основное условие- жилые помещения должны быть приспособлены для постоянного проживания людей с инвалидностью и отвечать установленным санитарным и техническим правилам и нормам. При организации сопровождаемого проживания должна быть обеспечена трудовая и дневная занятость людей. Цель внедрения технологий- нормализовать жизнь людей с инвалидностью, создав условия, замещающие обслуживание в стационаре на сопровождение и предоставление услуг в обычных местах проживания.

Впервые к проблеме организации проживания людей с инвалидностью во внебольничных условиях обратились в некоторых европейских странах. В частности, в Швеции нуждающимся в сопровождаемом проживании, предоставляются отдельные квартиры в социальных домах. Помощь по сопровождению оказывали персональные ассистенты. Для организации дневной занятости создавались специальные центры. Финансирование обеспечивало государство. Во Франции сопровождаемое проживание стало развиваться с середины XX в. в форме частных общинных поселений. Если первая община занимала один дом, в котором проживало 
30 человек, то сейчас- это подобие социальной системы, действующей во многих европейских странах, Канаде и США, насчитывающей 140 общин на религиозной основе (Ванье 2013). В Дании от интернатов отказались более пятнадцати лет назад в пользу реабилитации на уровне местных сообществ. Такая система дает возможность для людей с инвалидностью самостоятельно делать выбор- проживать в обычных условиях или в условиях повышенной социальной опеки в специализированном учреждении (Shepherd 1998). В Германии и Финляндии также отошли от тотальной изоляции людей с инвалидностью (Tanzman 1993). Если человеку с инвалидностью необходима постоянная помощь, которую он не может получить дома или в специализированной квартире, он может жить в специализированном учреждении- постоянно или временно. В Великобритании действует специальная программа «Поддержка», предусматривающая предоставление жилья людям с инвалидностью. Основные поставщики услуг определяются формой поддерживаемого проживания и уровнем зависимости клиентов (Урядницкая 2009).

Экономическая эффективность сопровождаемого проживания представлена в работе Джона Чишолма, который провел анализ затрат, связанных с изменением баланса между стационарной и альтернативной формой предоставления долговременной помощи пациентам (Chisholm 2001). В исследованиях, проведенных учеными США и Скандинавии, отмечалось повышение уровня самостоятельного социального функционирования и качества жизни подопечных в квартирах для совместного и группового проживания (Segal, Kofler 1993; Middleboe et al. 1998). Анализ зарубежного опыта показал преимущество стационарозамещающих практик по сравнению с закрытыми лечебными учреждениями и позволил выделить основные факторы, определяющие эффективность их развития: нормативноправое обеспечение, финансовое обеспечение (в т. ч. государственное), кадровое обеспечение, создание рынка социальных услуг (в т.ч. для обеспечения сопровождаемого проживания лиц с тяжелой инвалидностью), межведомственное взаимодействие и создание условий для обеспечения дневной и трудовой занятости инвалидов.

На основе опыта зарубежных стран в России реализуются программы сопровождаемого проживания. Первые проекты организованы в начале 2000-х гг. для лиц с психическими нарушениями в Санкт-Петербурге, Пскове, Москве и Владимире под руководством общественных организаций за счет средств грантовой поддержки и инвестиционных вложений (Кожушко и др. 2019; Tsarev 2017; Кац, Сторожук 2015). Долговое время развитие программ шло фрагментарно, на уровне отдельных субъектов РФ. Основные трудности связаны со слабой законодательной базой, малой долей участия государства в решении организационных и финансовых вопросов, недостатком жилых помещений, неприспособленностью инфраструктуры для лиц с ограниченными возможностями, неготовностью 
общества к принятию таких людей. Ратифицировав в 2012 г. «Конвенцию о правах инвалидов» (Конвенция ООН 2006), государство встало на защиту и обеспечение полной реализации людьми с инвалидностью прав и основных свобод: приняты новые федеральные законы в социальной сфере (2013; 2014), внесены изменения в действующие законодательные акты (Ф3 1995), утверждены перечень социальных услуг по видам социальных услуг (Постановление Правительства 2014) и методические рекомендации по организации различных технологий сопровождаемого проживания инвалидов (Приказ Минтруда России 2018), разработаны меры для улучшения доступности объектов и услуг инвалидам в рамках реализации государственной программы «Доступная среда» (Постановление Правительства 2015).

Вопросы организации сопровождаемого проживания нашли свое отражение в Государственной программе РФ «Доступная среда» на 2011 2020 гг., часть которой продлена до 2025 г. (Постановление Правительства 2019). Предусмотрена государственная поддержка таких проектов в субъектах РФ, при условии регионального софинансирования. Для оказания методической помощи в организации технологий сопровождаемого проживания ФГБУ ФНЦРИ им. Г.А. Альбрехта Минтруда России (далее Центр) определен методическим центром по вопросам формирования и развития системы комплексной реабилитации и абилитации инвалидов и детей-инвалидов, в том числе ранней помощи и сопровождаемого проживания (Приказ Минтруда России 2019). Центр проводит исследования, связанные с развитием в стране этого направления. По результатам мониторинга (по состоянию на начало 2020 г.) технологии сопровождаемого проживания реализуются в 69 субъектах РФ, однако опыт их реализации, а также уровень и динамика развития различны. Длительный опыт (более 10 лет) имеется в СанктПетербурге, Псковской и Владимирской областях (Кожушко и др. 2019; Tsarev 2017; Кац, Сторожук 2015)- их отличает проработанность нормативной правовой базы, развитие всех форм и этапов сопровождаемого проживания, большой охват людей с инвалидностью данной формой жизнеустройства. Другие субъекты- Рязанская область, Алтайский край- только в начале пути по организации стационарозамещающих технологий и проводят подготовительные работы (Альдашева, Сиротина 2017). Те регионы, где уже реализуются технологии, отличаются друг от друга по охвату нуждающихся людей в сопровождаемом проживании, формами их жизнеустройства, количеством открытых домов, перечнем предоставляемых услуг, объемом финансирования (Пономаренко 2019).

Для принятия управленческих решений при выборе и планировании мероприятий по улучшению доступности технологий сопровождаемого проживания необходимо учитывать особенности организации и уровень развития технологий в каждом субъекте РФ, что обуславливает более широкое изучение данной проблемы. Целью нашего исследования является 
анализ уровня и динамики развития сопровождаемого проживания в субъектах Российской Федерации.

В работе использованы результаты ежегодных мониторинговых исследований, представленных исполнительными органами власти всех субъектов РФ, по оценке доступности данной формы жизнеустройства для людей с инвалидностью, которые проводятся центром с 2018 г. Разработана система индикаторов по широкому кругу вопросов развития технологий сопровождаемого проживания. Выделены наиболее значимые индикаторы, отражающие системность и эффективность развития программ сопровождаемого проживания: наличие технологий и этапность их внедрения (А - подготовительный, В - учебный, C- постоянный); форма реализации (А - индивидуальная, В - групповая); виды помещений для реализации учебного этапа (A- квартиры жилого фонда, В - помещения квартирного типа в стационарных учреждениях); виды жилых помещений для реализации постоянного этапа (А- квартиры жилого фонда, В - помещения квартирного в стационарных учреждениях); численность людей с инвалидностью, находящихся на сопровождаемом проживании (А- 100 чел. и больше, В - от 50 включительно до 100 человек, С-менее 50 человек); динамика их охвата за год (A-20\% и выше, В- от 10\% включительно до 20\%, С- менее 10\%); нормативно-правовые акты субъекта (НПА), обеспечивающие реализацию технологий сопровождаемого проживания (A-приняты, B-запланированы к принятию в текущем году, C- отсутствие в планах на текущий год); трудовая и дневная занятость инвалидов на сопровождаемом проживании (доля охвата инвалидов: А- 80\% и выше, Вот $50 \%$ включительно до $80 \%$; С- ниже 50\%); подготовленность специалистов (А- $80 \%$ и более, В- от 50\% включительно до $80 \%$, менее $50 \%$ ); наличие финансирования (А- имеется, В - запланировано на текущий год, $\mathrm{C}$ - отсутствие в планах на текущий год). Индикаторы оценивались по состоянию на январь 2020 г., те из них, которые требовали сравнения в динамике, оценивались по состоянию на январь 2019 и 2020 гг.

\section{Определение уровня и степени развития технологий сопровождаемого проживания в субъектах РФ}

На основании выделенных индикаторов все субъекты РФ распределены на семь групп в зависимости от уровня и степени развития технологий сопровождаемого проживания-от очень высокого до очень низкого. Первый уровень - очень высокий - для него характерна реализация всех этапов и форм сопровождаемого проживания, преимущественно в помещениях жилого фонда, с численностью проживающих выше 100 чел., с охватом за год- более $20 \%$ нуждающихся в сопровождаемом проживании, наличие НПА, организация трудовой и дневной занятости с охватом более $80 \%$ проживающих, наличие более $80 \%$ 
квалифицированных кадров, достаточное финансирование и наличие запланированных мероприятий по развитию направления.

Результаты исследования показывают, что очень высокий уровень и степень развития технологий сопровождаемого проживания определяется только в Санкт-Петербурге (1,2\%). Реализация программ проходит на всех этапах, в индивидуальной и групповой форме, как в квартирах жилого фонда, так и в учреждениях социального обслуживания. За год число вовлеченных людей с инвалидностью выросло на 30,6\% (со 186 до 243 чел.). Обеспечена их трудовая и дневная занятость. В полном объеме проработаны вопросы по нормативно-правовому обеспечению, вопросы межведомственного взаимодействия, предоставления инвалидам жилья в специализированном жилом фонде. Размер софинансирования в Санкт-Петербурге самый высокий в России, в 2019 г. выделено 59135 тыс. руб. В мероприятиях и оказании услуг принимают участие как государственные, так и негосударственные и общественные организации.

Второй уровень - высокий. На этом уровне реализуются все этапы и формы сопровождаемого проживания, постоянный этап организуется преимущественно в помещениях жилого фонда, численность охваченных сопровождаемым проживанием инвалидов от 50 до 100 чел., динамика охвата за год от 10 до 20\%, большая часть (80\%) обеспечена трудовой или дневной занятостью, более $80 \%$ работающих специалистов прошли обучение, приняты законодательные и правовые акты, имеется достаточное финансирование и наличие запланированных мероприятий по развитию. Такой уровень характерен для семи субъектов РФ (8,2\%)- Волгоградской, Курганской, Ленинградской, Псковской, Пензенской, Тюменской и Иркутской областей. В отличие от предыдущего уровня характеризуется меньшим охватом инвалидов.

Третий уровень- выше среднего. Для него характерна реализация всех этапов и форм сопровождаемого проживания, организация постоянного этапа в помещениях жилого фонда (с численностью до 50 чел) и/или в нескольких стационарных организациях (с общей численностью больше 100 чел.), динамика охвата за год от 10 до 20\%, в трудовую и дневную занятость включены от 50 до 80\%, квалифицированных специалистов от 50 до $80 \%$, наличие принятых НПА в регионе, достаточное финансирование и наличие запланированных мероприятий. Доля субъектов с данным уровнем развития составляет 5,9\%- Пермский край, Владимирская, Ярославская, Кировская, Новосибирская области.

Четвертый уровень- средний. На этом уровне также реализуются все этапы сопровождаемого проживания, организованы учебный и постоянный этапы преимущественно в помещениях квартирного типа с общей численностью от 50 до 100 чел. Динамика охвата инвалидов за год от 10 до 20\%, в трудовую и дневную занятость вовлечены от 50 до 80\%, подготовленных специалистов от 50 до $80 \%$, в регионе есть принятые НПА и запланированы 
мероприятия по развитию с обеспечением финансирования. Такой уровень развития характерен для 21 субъекта РФ (24,7\%): г. Москвы, Белгородской, Ивановской, Тверской, Московской, Костромской, Липецкой, Омской, Калужской, Архангельской, Астраханской, Вологодской, Нижегородской, Свердловской, Томской и Амурской областей, Приморского и Ставропольского края, Ханты-Мансийского АО, Республики Коми и Бурятии.

Пятый уровень - ниже среднего. Здесь преимущественно реализуется учебный этап сопровождаемого проживания, но запланированы мероприятия и их финансовое обеспечение для реализации постоянного этапа; при наличии постоянного этапа в программы сопровождаемого проживания включается до 20 чел., динамика охвата за год менее $10 \%$, доля охвата трудовой и дневной занятостью от 50 до 80\%, финансирование отсутствует, НПА в процессе разработки. В эту группу входит 29 субъектов РФ (34,1\%): Брянская, Воронежская, Курская, Орловская, Смоленская, Тамбовская, Тульская, Калининградская, Новгородская, Ростовская, Оренбургская, Самарская, Саратовская, Ульяновская, Челябинская, Кемеровская, Сахалинская и Мурманская области, Чеченская, Удмуртская республики, Карелия, Татарстан, Тыва, Башкортостан, Мордовия, а также Красноярский, Забайкальский, Камчатский и Хабаровский край.

Шестой уровень - низкий. На этом уровне реализуется преимущественно подготовительный этап, учебный и остальные этапы отсутствуют в планах мероприятий по дальнейшему развитию, финансирование не выделяется. Низкий уровень и динамика развития технологий сопровождаемого проживания зафиксирован в шести субъектах РФ (7,1\%): Рязанской и Магаданской областях, Алтайском крае, республиках Хакасия, Саха (Якутия) и Кабардино-Балкария.

Седьмой уровень - крайне низкий, когда программы сопровождаемого проживания не реализуются. Такой уровень имеет место в 16 (18,8\%) субъектах РФ: Ямало-Ненецком АО, Чукотском АО, Ненецком АО, Еврейском АО, Краснодарском крае, республике Крым, Севастополе, в республиках Адыгея, Марий-Эл, Алтай, Калмыкия, Дагестан, Ингушетия, Северная-Осетия (Алания), Карачаево-Черкессия и Чувашия.

Таким образом, результаты анализа показали, что в целом в России, проекты сопровождаемого проживания мало развиты- большинство субъектов (60\%) имеют уровень развития ниже среднего, низкий и крайне низкий (рис. 1). Анализ выявил основные проблемы, препятствующие внедрению программ сопровождаемого проживания и влияющие на уровень и степень их развития: отсутствие жилых помещений- 84,7\%; неразвитость нормативно-правовой базы федерального уровня- 65,9\%; недостаточность нормативно-правовой базы регионального уровня- 78,2\%, дефицит подготовленных кадров- 72,9\%; низкий уровень финансирования- $62,4 \%$.

Во многих регионах в ближайшие годы запланированы к реализации ряд мероприятий, направленных на преодоление барьеров сопровождаемого 
проживания. В частности, в Липецкой и Свердловской областях для целей сопровождаемого проживания запланировано выделение муниципальных квартир на условиях социального найма; в Ярославской области и Хабаровском крае строятся дома сопровождаемого проживания; в Воронежской области запланировано создание отделений сопровождаемого проживания на базе стационарных организаций социального обслуживания с целью подготовки к самостоятельному проживанию. Различные меры по решению жилищных вопросов запланированы еще в 15 регионах. Финансирование сопровождаемого проживания в субъектах РФ предлагалось решать двумя путями: за счет выделения средств из регионального бюджета (Белгородская, Воронежская, Курская области, Республика Коми) и за счет привлечения средств инвесторов (Орловская область, Республика Башкортостан). В 22 субъектах РФ приняты региональные нормативные правовые акты по решению различных вопросов организации сопровождаемого проживания, в 46 субъектах для работы в проектах запланирована подготовка специалистов.

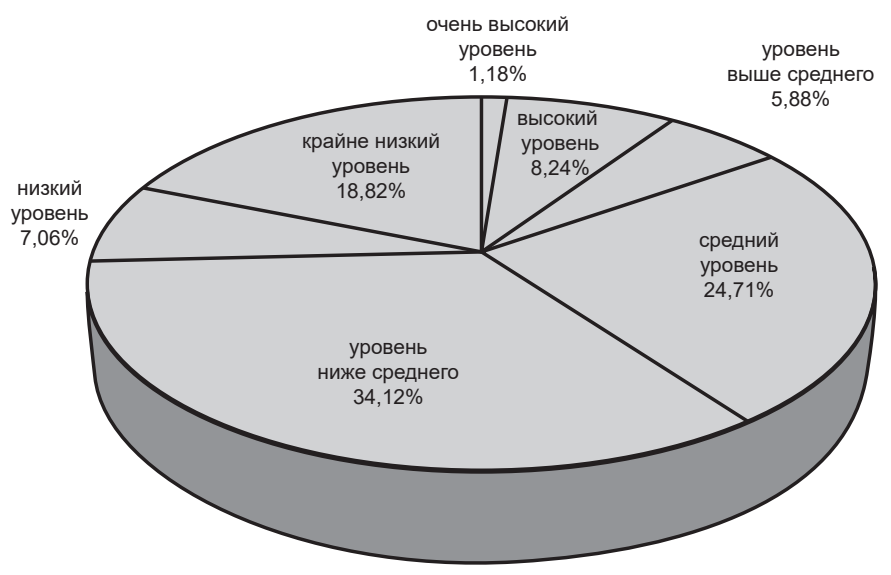

Рисунок 1. Уровень и динамика развития технологий сопровождаемого проживания в Российской Федерации.

\section{Особенности организации технологии сопровождаемого проживания в Санкт-Петербурге}

Для изучения опыта и ознакомления с инновационными подходами, наибольший интерес представляют регионы с высоким и очень высоким уровнем развития стационарозамещающих технологий. С этой целью проведен углубленный анализ мероприятий, реализуемых в СанктПетербурге, как регионе-лидере с очень высоким уровнем программ 
сопровождаемого проживания. Выявлены особенности организации мероприятий в Санкт-Петербурге: здесь законодательно предусмотрено выделение квартир для людей с инвалидностью в специализированном жилищном фонде города (Закон Санкт-Петербурга 2006); расширен (более чем в три раза- с 30 услуг до 108 услуг) федеральный перечень социальных услуг (Закон Санкт-Петербурга 2014); выделены в отдельную группу инвалиды трудоспособного возраста с нарушениями умственного развития, в том числе проживающие в квартирах социального назначения (Постановление правительства СПб 2014а); разработан оригинальный механизм предоставления социальных услуг по РИПСО (рекомендуемая индивидуальная программа социального обслуживания) с выделением дифференцированных наборов (75 вариантов) в зависимости от состояния здоровья и тяжести ограничений жизнедеятельности (Распоряжение комитета СПб 2016); определен размер и порядок выплаты компенсации поставщику (поставщикам) социальных услуг, которые включены в реестр поставщиков социальных услуг Санкт-Петербурга, но не участвуют в выполнении государственного задания (Постановление правительства СПб 2014b); обеспечено тесное взаимодействие органов исполнительной власти, общественных организаций города и бизнеса в решении вопроса жизнеустройства людей с инвалидностью, нуждающихся в сопровождении; разработаны типовые обучающие программы для подготовки кадров.

Полное нормативное правовое регулирование в области социальной защиты людей с инвалидностью, развитие различных этапов и форм сопровождаемого проживания, большой охват нуждающихся и установление индивидуального подхода к предоставлению социальных услуг, определило лидерство Санкт-Петербурга в рейтинге уровня и степени развития технологий среди субъектов РФ. Опыт Санкт-Петербурга, несомненно, ценен для изучения и тиражирования в других субъектах РФ.

\section{Заключение}

Распределение регионов в зависимости от уровня развития ключевых индикаторов технологий сопровождаемого проживания, полученное в результате интегрального анализа, позволило выделить две наиболее характерные черты: (1) в комплексной реабилитации и абилитации инвалидов технологии сопровождаемого проживания находятся на этапе становления, об этом свидетельствует большое количество субъектов РФ с уровнем и степенью развития ниже среднего; (2) при последовательном переходе от кластера к кластеру прослеживается определенная логичная взаимосвязь между исследуемыми параметрами: показатели всех блоков имеют закономерность к повышению в зависимости от возрастания кластерных групп, что дает возможность проанализировать каждую группу в отдельности, выявить отстающие блоки показателей и выработать систему мер по их повышению. 
В качестве основных мер для повышения уровня реализации программ сопровождаемого проживания предлагается: изучение и использование передового опыта Санкт-Петербурга; разработку нормативных правовых и методических документов по организации технологий сопровождаемого проживания; формирование реестра нуждающихся в данной форме жизнеустройства; разработку методических рекомендаций для определения готовности людей с инвалидностью к сопровождаемому проживанию и порядка его проведения; определение регламентов предоставления социальных услуг; организацию, координацию и межведомственное взаимодействие по вопросам сопровождаемого проживания (органов власти и общественных организаций), поиск полномочий участников, правовое закрепление отношений между ними; определение финансовых источников сопровождаемого проживания (государственных, негосударственных); обучение специалистов; проведение информационной работы среди населения, а также включение людей с инвалидностью в принятие решений выбора места жительства и социального окружения, в определение вида и объема необходимой помощи.

Результаты исследования имеют практическую значимость, так как могут быть использованы при планировании мероприятий на федеральном и региональном уровнях. Внедрение технологий сопровождаемого проживания будет способствовать повышению качества жизни людей с инвалидностью, реализации их права на самостоятельный образ жизни и включению в жизнь общества. Вместе с тем необходимо продолжать исследование по изучению мнения людей с инвалидностью о сопровождаемом проживании и реальном положении дел на местах. Исследование реализации таких программ только по объективным показателям и отчетам исполнительных органов имеет ряд ограничений (мы видим цифры, но ничего не знаем о том, насколько людям хорошо или плохо в конкретных программах, насколько они сами оценивают свое «социальное функционирование», возможности трудоустройства, реабилитации). Представляется важным дополнить это исследование формальных показателей перспективами самих людей, участвующих в подобных программах.

\section{Материалы для анализа}

Закон Санкт-Петербурга (2006) О специализированном жилищном фонде СанктПетербурга, № 100-15 от 04.04.2006.

Закон Санкт-Петербурга (2014) О социальном обслуживании населения в СанктПетербурге, № 717-135 от 24.12.2014.

Конвенция ООН (2006) О правах инвалидов, от 13.12.2006.

Постановление Правительства РФ (2014) Об утверждении примерного перечня сочиальных услуг, № 1236 от 24.11.2014. 
Постановление Правительства РФ (2015) Об утверждении государственной программь Российской Федерации «Доступная среда» на 2011-2020 г2., № 1297 от 01.12.2015.

Постановление Правительства РФ (2019) «Об утверждении государственной программы Российской Федерачии «Доступная среда» № 363 29.03.2019.

Постановление правительства Санкт-Петербурга (2014а) Об утверждении Положения о размере и порядке выплаты компенсаџии поставщику или поставщикам социальных услуг, которые включены в реестр поставщчиков сочиальных услуг Санкт-Петербурга, но не участвуют в выполнении государственного задания (заказа), при получении у них гражданином социальных услуг, предусмотренных индивидуальной программой № 1288 г. от 29.12.2014.

Постановление Правительства Санкт-Петербурга (2014b) Об утверждении порядков предоставления социальных услуг поставщиками социальных услуг в СанктПетербурге» N 1283 от 29.12.2014.

Приказ Минтруда России (2019) Об определении научных организаиий, подведомственных Министерству труда и социальной защиты Российской Федерации, в качестве методических иентров комплексной реабилитации и абилитациии инвалидов и детейинвалидов, № 46 от 29.01.2019.

Приказ Минтруда России (2018) Об утверждении методических рекомендаций по организации различных технологий сопровождаемого проживания инвалидов, в том числе такой технологии, как сопровождаемое совместное проживание мальхх групп инвалидов в отдельных жилых помещеения, N 847 от 14.12.2017.

Распоряжение Комитета по социальной политике Санкт-Петербурга (2016) Об утверждении рекомендуемых индивидуальных программ социального обслуживания получателей сочиальных услуг в разрезе форм сочиального обслуживания, видов социальных услуг и категорий получателей сочиальных услуг в Санкт-Петербурге, № 466-р от 29.12.2016.

Федеральный закон РФ (1995) О соичильной защчите инвалидов в Российской Федерациии, № 181-ФЗ от 24.11.1995.

Федеральный закон РФ (2013) Об основах соииального обслуживания граждан в Российской Федераиии, № 442-Ф3 от 28.12.2013.

Федеральный закон РФ (2014) О внесении изменений в отдельные законодательные акты Российской Федерачии по вопросам социальной защиты инвалидов в связи с ратификацией Конвенции о правах инвалидов, N 419-ФЗ от 01.12.2014. 


\section{Список источников}

Альдашева А.Б., Сиротина Т.В. (2017) Сопровождаемое проживание лии с инвалидностью: возможности реализации в Алтайском крае. Барнаул: Графикс.

Ванье Ж. (2013) Войти в тайну. Иисус в Евангелии от Иоанна. М.: Вера и Свет.

Кац Л.И., Сторожук Ю.М (2015) Формы сопровождаемого проживания во Владимирской области. Владимир: Свет.

Кожушко Л.А., Гордиевская Е. О., Демина Э.Н. (2019) Сопровождаемое проживание: опыт, проблемы, перспективы развития. Физическая и реабилитационная медицина, 1 (2): $26-36$.

Пономаренко Г.Н. (ред.) (2019) Сопровождаемое проживание. Организационные и методические основы. СПб: Циацан.

Урядницкая Н.А. (2009) Самоопределение и самостоятельная жизнь. Синдром Дауна. ХХІ век: междисииплинарный научно-практический журнал, (3):37-40.

Chisholm D., Hallam A. (2001) Changes to the Hospital-community Balance of Mental Health Care: Economic Evidence from Two UK Studies. Kirkland: Hogrefe \& Huber.

Middleboe T., Mackeprang T. Thalsgaard A., Christiansen P. (1998) A Housing Support Programme for the Mentally Ill: Need Profile and Satisfaction among User. Acta Psychiatrica Scandinavica, 98 (4):321-327.

Segal S.P., Kofler P.L. (1993) Sheltered Care Residences: Ten-year Personal Outcomes American. Journal of Orthopsychiatry, 63 (1): 80-91.

Shepherd G. (1998) System Failure? The Problems of Reductions in Long Stay Beds in the UK. Epidemiology and Social Psychiatry, 7 (2): 127-134.

Tanzman B. (1993) An Overview of Surveys of Mental Health Consumers' Preferences for Housing and Support Services. Hospital and Community Psychiatry, 44 (5): 450-455.

Tsarev A. M. (ed.) (2017) Life with Dignity. Practical Guide. Moscow: Feather. 


\section{RATINGS OF THE CONSTITUENT ENTITIES OF THE RUSSIAN FEDERATION BY DEVELOPMENT LEVEL OF ASSISTED LIVING FOR DISABLED PEOPLE}

The article analyses a new direction in the development of multilevel rehabilitation of people with disabilities - assisted living. Based on the results of assessing the level of development and dynamics, a rating of the constituent entities of the Russian Federation was compiled, allowing a comparison of the positions of different regions, which can identify their strengths and weaknesses, and act as a tool for developing and planning measures to further improve this area in the country. The study was conducted based on an analysis of materials from annual monitoring submitted by the executive authorities of the eighty-five constituent entities of the Russian Federation. Ten indicators were taken into account as assessment criteria, reflecting the consistency and efficiency of the development of accompanied living. Methods of parametric statistics were used to process the results. As a result, all subjects were divided into groups - from very high levels of assisted living to extremely low. As the study showed, the presence of a large number of regions with a level and development below the average indicates that the formation of technologies for assisted living is at the initial stage of development. The main measures to increase the level of implementation of the accompanied residence programs are development of normative legal and methodological documents in this area; formation of a register of those in need of this form of life arrangement; development of regulations for the provision of social services; the organization, coordination and interdepartmental interactions on the issues of accompanied accommodation; the identification of sources of funding for technologies; the training of specialists; carrying out information work among the population. The proposed measures can be used to improve programs for the development of assisted living and to determine approaches to deinstitutionalization of the boarding system in Russia as a whole.

Keywords: assisted living, disability, quality of life, rating of the subjects of the Russian Federation, level and dynamics of development

DOI: 10.17323/727-0634-2021-19-4-701-714

Ludmila A. Kozhushko- Cand. Sci. (Med.), Head of the Department of Social Rehabilitation and Habilitation of Disabled Persons at the Federal Research Center for the Rehabilitation of Disabled People named after of G. A. Albrecht Ministry of Labour and Social Protection of the Russian Federation, St. Petersburg, Russian Federation. Email: 1.timch@mail.ru

Oksana N. Vladimirova- Cand. Sci. (Med.), Director of the Institute of Rehabilitation and Habilitation of Disabled Persons of the Federal Research Center for the Rehabilitation of Disabled People named after G. A. Albrecht of the Ministry of Labour and Social Protection of the Russian Federation, St. Petersburg, Russian Federation. Email: vladox1204@yandex.ru 


\section{References}

Al'dasheva A.B., Sirotina T.V. (2017) Soprovozhdaemoe prozhivanie lic s invalidnost'ju: vozmozhnosti realizacii v Altajskom krae [Assisted Living of Persons with Disability: Possibilities for Altay Krai]. Barnaul: Grafiks.

Chisholm D., Hallam A. (2001) Changes to the Hospital-community Balance of Mental Health Care: Economic Evidence from Two UK Studies. Kirkland: Hogrefe \& Huber.

Kats L. I., Storozhuk Yu.M. (2015) Formy soprovozhdaemogo prozhivaniya vo Vladimirskoy oblasti [Forms of Assisted Living in the Vladimir Region]. Vladimir: Svet.

Kozhushko L.A., Gordievskaya E. O., Demina E. N. (2019) Soprovozhdaemoe prozhivanie: opyt, problemy, perspektivy razvitiya [Assisted Living: Experience, Problems, Development Prospects. Physical and Rehabilitation Medicine]. Fizicheskaya i reabilitatsionnaya meditsina [Physical and Rehabilitation Medicine], 1 (2):26-36.

Middleboe T., Mackeprang T. Thalsgaard A., Christiansen P. (1998) A Housing Support Programme for the Mentally Ill: Need Profile and Satisfaction among User. Acta Psychiatrica Scandinavica, 98(4): 321-327.

Ponomarenko G. N. (ed.) (2019) Soprovozhdaemoe prozhivanie. Organizacionnye i metodicheskie osnovy [Assisted Living. Organizational and Methodological Foundations]. St. Petersburg: Ciacan.

Segal S.P., Kofler P.L. (1993) Sheltered Care Residences: Ten-year Personal Outcomes American. Journal of Orthopsychiatry, 63 (1): 80-91.

Shepherd G. (1998) System Failure? The Problems of Reductions in Long Stay Beds in the UK. Epidemiology and Social Psychiatry, 7 (2): 127-134.

Tanzman B. (1993) An Overview of Surveys of Mental Health Consumers' Preferences for Housing and Support Services. Hospital and Community Psychiatry, 44 (5): 450-455.

Tsarev A. M. (ed.) (2017) Life with Dignity. A Practical Guide. Moscow: Feather.

Urjadnickaja N. A. (2009) Samoopredelenie i samostojatel'naja zhizn' [Self-determination and Independent Living]. Sindrom Dauna. XXI vek: mezhdisciplinarnyj nauchno-prakticheskij zhurnal [Down Syndrome. XXI Century: Interdisciplinary Scientific and Practical Journal], (3): 37-40.

Vanier J. (2013) Vojti v tajnu. Iisus v Evangelii ot Ioanna [Enter the Secret. Jesus in the Gospel of John]. Moscow: Vera i Svet. 